\title{
Relationship Between Sudden Death Syndrome caused by Fusarium virguliforme and Soybean Yield: A Meta-Analysis
}

\author{
Yuba R. Kandel, ${ }^{1}$ Carl A. Bradley, ${ }^{2}$ Martin I. Chilvers, ${ }^{3}$ Febina M. Mathew, ${ }^{4}$ Albert U. Tenuta, ${ }^{5}$ Damon L. Smith, ${ }^{6}$ Kiersten A. Wise, ${ }^{2}$ \\ and Daren S. Mueller ${ }^{1, \dagger}$ \\ ${ }^{1}$ Department of Plant Pathology and Microbiology, Iowa State University, Ames 50011, U.S.A. \\ ${ }^{2}$ Department of Plant Pathology, University of Kentucky Research and Education Center, Princeton 42445, U.S.A. \\ ${ }^{3}$ Department of Plant, Soil and Microbial Sciences, Michigan State University, East Lansing 48824, U.S.A. \\ ${ }^{4}$ Department of Agronomy, Horticulture and Plant Science, South Dakota State University, Brookings 57007, U.S.A. \\ ${ }^{5}$ Ontario Ministry of Agriculture, Food, and Rural Affairs, Ridgetown, ON NOP2C0, Canada \\ ${ }^{6}$ Department of Plant Pathology, University of Wisconsin-Madison, Madison, 53706, U.S.A.
}

\begin{abstract}
In total, 52 uniform field experiments were conducted in Illinois, Indiana, Iowa, Michigan, South Dakota, and Wisconsin in the United States and Ontario, Canada from 2013 to 2017 comparing crop protection products against sudden death syndrome (SDS) of soybean. Data were analyzed using meta-analytic models to summarize the relationship between foliar disease index (FDX) and yield. For each study, correlation and regression analyses were performed separately to determine three effect sizes: Fisher's transformation of correlation coefficients $\left(Z_{r}\right)$, intercept $\left(\beta_{0}\right)$, and slope $\left(\beta_{1}\right)$. Random- and mixed-effect meta-analyses were used to summarize the effect sizes. Study- and location-specific moderator variables FDX

fixed effects. The overall mean effect sizes of transformed correlation coefficient $\bar{Z}_{r}$ was -0.41 and different from zero $(P<0.001)$, indicating that yield was negatively correlated with FDX. The $\bar{Z}_{r}$ was affected by disease level $(P<0.01)$ and cultivar $(P=0.02)$, with a greater effect at higher disease levels and with susceptible cultivars. The mean $\bar{\beta}_{0}$ was $4,121 \mathrm{~kg} / \mathrm{ha}$ and mean $\bar{\beta}_{1}$ was $-21 \mathrm{~kg} / \mathrm{ha} / \%$ FDX and were different from zero $(P<$ $0.01)$. Results from these data indicate that, for every unit of FDX increase, yield was decreased by $0.5 \%$. Study locations and year affected the $\bar{\beta}_{0}$, whereas none of the moderator variables significantly affected $\bar{\beta}_{I}$.
\end{abstract} (low $<10 \%$ and high $\geq 10 \%$ ), date of planting (early = prior to 7 May, conventional $=7$ to 21 May, and late $=$ after 21 May) cultivar (susceptible and partially resistant to SDS), study location, and growing season were used as
Keywords: correlation, field crops, fungi, oilseeds and legumes, regression, sudden death syndrome, yield loss and economic impacts
Sudden death syndrome (SDS) of soybean (Glycine max (L.) Merr.) is caused primarily by a soilborne fungus, Fusarium virguliforme O'Donnell \& T. Aoki (Aoki et al. 2003), in the United States and Canada. SDS was first reported in Arkansas in 1971 (Hirrel 1983). Since its first discovery, the disease has become widespread throughout most soybean-producing regions (Hartman et al. 2015a) and has become a leading threat of soybean production (Allen et al. 2017). SDS was placed as one of the top 10 yield-reducing soybean diseases in the United States, often ranking from second to fifth in importance from 1996 to 2014 (Allen et al. 2017; Wrather and Koenning 2009). In 2014, this disease caused an estimated loss of nearly 1.7 million metric tons in the United States, valued at approximately $\$ 617$ million (Allen et al. 2017).

When $F$. virguliforme infects soybean, root rot may occur in addition to the commonly observed interveinal chlorosis and necrosis of the leaves. F. virguliforme resides as a chlamydospore in soil, as mycelium on crop residue, or on cysts of soybean cyst nematode (SCN), and starts infecting soybean roots immediately after they emerge from the seed (Gongora-Canul and Leandro 2011). Cool and wet conditions in early spring favor root rot (Gongora-Canul and Leandro

\section{${ }^{\dagger}$ Corresponding author: D. S. Mueller; dsmuelle@iastate.edu}

Funding: Partial funding for field research in the United States was available by soybean checkoff through the North Central Soybean Research Program and United Soybean Board, Bayer CropScience, and BASF. In Canada, the Grain Farmers of Ontario, which obtained funding through the Ontario Farm Innovation Program, a component of Growing Forward 2, provided partial funding for field research.

The author(s) declare no conflict of interest.

Accepted for publication 14 January 2020.

(C) 2020 The American Phytopathological Society
2011). Foliar symptoms are usually observed when plants reach their reproductive stages, generally at R3 and R4 (pod development) stages (Fehr et al. 1971; Hartman et al. 2015b; Roy et al. 1997). Under conducive environments, particularly rainy weather (approximately 12 to $15 \mathrm{~cm}$ of precipitation per month) (Kandel et al. $2016 b$ ), toxins produced by $F$. virguliforme in roots are transported acropetally through the xylem after the start of pod development (growth stage R3), eventually accumulating in the foliage (Jin et al. 1996). Accumulation of the toxins, primarily FvTox1 (Brar et al. 2011; Pudake et al. 2013), in the foliage results in foliar symptoms. Foliar symptoms are seen as chlorotic and necrotic lesions in between veins, premature defoliation, and flower and pod abortion. Warm temperatures $\left(22\right.$ to $\left.24^{\circ} \mathrm{C}\right)$ and high soil moisture favor foliar symptom development (Scherm and Yang 1996). Foliar symptoms may not be expressed if weather does not favor foliar symptom development, even if roots are severely infected early in the season (Wang et al. 2019). SDS symptoms can be very striking and often appear in fields with high yield potential (Hartman et al. 2015b). SDS can cause devastating yield losses when severe but losses will depend on the timing of disease occurrence in the field, the cultivar's genetic makeup, and weather conditions (Hartman et al. 2015a; Roy et al. 1997).

SDS affects soybean yield in many ways (Njiti et al. 1998b) and it can range from unobservable to $100 \%$ loss on an individual plant basis (Hartman et al. 2015a). Early-season root infections can result in degradation of the root system and, therefore, reduce the root's ability to acquire water and nutrients from the soil. Necrotic and chlorotic lesions on leaves and premature defoliation affect the photosynthetic capacity of plants, which results in reduced dry matter for grain fill. Undersized seed is mainly due to less plant growth or dry matter accumulation, premature plant death, or combinations of these (Roy et al. 1997). Severe SDS during pod and flower formation reduces seed number by inducing pod and flower abortion. Noticeable pod abortion is more likely to occur when severe SDS occurs by early pod fill (Njiti et al. 1998b). Demonstrating yield loss caused by 
SDS specifically has been challenging due to large experimental variability and interactions of $F$. virguliforme with one or more abiotic and biotic factors, especially SCN (Roy et al. 1997). Some reports that investigated the relationship between SDS and yield showed a negative relationship and suggested that SDS can cause severe yield loss (de Farias Neto et al. 2006; Kandel et al. 2016a; Luo et al. 2000; Njiti et al. 1998b; Roy et al. 1997; Rupe et al. 1993, 1997; Sjarpe et al. in press) while other studies reported no correlation (Hershman et al. 1990; Scherm and Yang 1996). Varietal response to root rot and foliar symptoms may vary because of the different resistance genes or quantitative trait loci conferring resistance to the root rot or foliar symptoms, which can further complicate the relationship between SDS symptoms and yield (Njiti et al. 1998a; Tan et al. 2019).

Field studies have been conducted every year in multiple U.S. locations and Ontario, Canada to test the efficacy of fungicides, biopesticides, and other crop protection products that have been labeled or marketed for SDS management in soybean since 2013. The availability of the large amount of data from those field studies provides a unique opportunity to analyze and explore the relationship between SDS epidemics and yield. In the present study, original data on foliar disease and yield from both published (Kandel et al. 2016a, 2019) and unpublished studies were collected from SDS trials conducted to test various treatments in the aforementioned locations during 2013 to 2017. Previously, these data have been used to explore their efficacies for SDS management; here, we examine the relationship between SDS and yield.

In this study, data were analyzed using a meta-analysis, which is a statistical technique that can synthesize data from several individual studies (Madden and Paul 2011). Qualitative synthesis of results from individual studies can be difficult and misleading when sample size varies and results are contradictory. When sufficient data from individual studies are available, a meta-analysis provides more insight than that given by individual study analysis methods. Metaanalysis minimizes the shortfalls of qualitative synthesis and provides more meaningful output.

The main objectives of this study were to use a meta-analysis approach to (i) determine the relationship of yield to SDS foliar symptoms and (ii) identify variables affecting the relationship between SDS and yield. This information is essential to estimate loss in yield at the field level due to SDS and assist farmers with making informed decision about SDS management.

\section{Materials and Methods}

Disease and yield data collection. Field studies were conducted in Illinois, Indiana, Iowa, Michigan, South Dakota, and Wisconsin in the United States and Ontario, Canada from 2013 to 2017. These studies were conducted under a wide geographic range and under different SDS levels, comparing various seed treatment fungicides, biopesticides, and foliar crop protection products in commercially available SDS-resistant and -susceptible cultivars. Each year, 12 to 14 field trials (combinations of location and cultivar) were conducted. Levels of SDS were manipulated in these studies through the use of several seed treatments, different cultivars, artificial infestation, irrigation, and field selection. Irrigation and infestation with $F$. virguliforme are routinely used to increase the severity of SDS in field research trials (de Farias Neto et al. 2006). Treatments tested were chosen based on the commonly promoted products for SDS management in the United States and Canada to test their efficacy against SDS. Treatments tested in each year are listed in Table 1. In summary, treatments included a nontreated check, fungicide seed treatment, foliar fungicides, biological pesticides, nematistats, herbicides, and commercial base seed treatments from Bayer CropScience, Syngenta Crop Protection LLC, and Monsanto that included a combination of fungicide and insecticide active ingredients.

Soybean cultivars differed by year and location and were selected based on their reaction to SDS. In all site-years, there was a minimum of one susceptible and one partially resistant cultivar. A location-cultivar combination was considered to be an independent "study" in the meta-analysis described below, with a total number of 68 studies in the dataset. Those studies that did not report yield $(n=2)$ or disease $(n=14)$ were not included in the analysis; therefore, the total number of studies used for these analyses was 52 .

To increase the chances of SDS development, most studies were sown as soon as the ground was ready for planting. Dates of planting ranged from the third week of April to second week of June. Field studies were inoculated and irrigated at many locations to ensure uniform disease pressure within a field trial. In all of the studies, soybean crop and weed management practices were followed based on local recommendations. A plot (experimental unit) size was at least four rows wide, with interrow spacing of 38 to $76 \mathrm{~cm}$ and length of $5.3 \mathrm{~m}$. The middle rows were rated for disease and harvested for yield following the methods described elsewhere (Kandel et al. 2016a, 2019). Yields were calculated as kilograms per hectare, adjusted to $13 \%$ moisture.

Table 1. List of treatments tested in field trials in the states of Illinois, Indiana, Iowa, Michigan, Wisconsin, and South Dakota in the United States and Ontario, Canada between 2013 and 2017

\begin{tabular}{|c|c|}
\hline Year, treatment ${ }^{\mathrm{a}}$ & Citation \\
\hline \multicolumn{2}{|l|}{2013,2014} \\
\hline $\begin{array}{l}\text { Commercial base seed treatment from } \\
\text { Bayer CropScience }\end{array}$ & Kandel et al. 2016 a \\
\hline Fluopyram (ILEVO; BASF) & $\ldots$ \\
\hline Pyraclostrobin (Headline EC; BASF) & $\ldots$ \\
\hline $\begin{array}{l}\text { Pyraclostrobin + fluxapyroxad (Priaxor; } \\
\text { BASF) }\end{array}$ & $\ldots$ \\
\hline $\begin{array}{l}\text { Trifloxystrobin + prothioconazole } \\
\quad \text { (Stratego YLD; Bayer CropScience) }\end{array}$ & $\ldots$ \\
\hline \multicolumn{2}{|l|}{2015,2016} \\
\hline $\begin{array}{l}\text { Commercial base seed treatment from } \\
\text { Bayer CropScience and Syngenta Crop } \\
\text { Protection }\end{array}$ & Kandel et al. 2019 \\
\hline $\begin{array}{l}\text { Citric acid (Procidic; Greenspire } \\
\text { Global Inc.) }\end{array}$ & $\ldots$ \\
\hline $\begin{array}{l}\text { Fluopyram + clothianidin + Bacillus firmus } \\
\text { (Poncho Votivo; BASF) }\end{array}$ & $\cdots$ \\
\hline $\begin{array}{l}\text { Fluoxastrobin + flutriafol (Fortix; } \\
\text { Cheminova Inc.) }\end{array}$ & $\ldots$ \\
\hline $\begin{array}{l}\text { Lactofen (Cobra; Valent U.S.A. } \\
\text { Corporation) }\end{array}$ & $\ldots$ \\
\hline $\begin{array}{l}\text { Saponins extract of Chenopodium quinoa } \\
\text { (Heads Up; Heads Up Plant Protectants, } \\
\text { Inc.) }\end{array}$ & $\ldots$ \\
\hline $\begin{array}{l}\text { Thiabendazole (Mertect 340-F; Syngenta } \\
\text { Crop Protection LLC) + P. nishizawae } \\
\text { Pn1 (Clariva; Syngenta Crop Protection } \\
\text { LLC) }\end{array}$ & $\ldots$ \\
\hline \multicolumn{2}{|l|}{2017} \\
\hline $\begin{array}{l}\text { Commercial base seed treatments from } \\
\text { Bayer CropScience and Monsanto }\end{array}$ & Unpublished \\
\hline $\begin{array}{l}\text { Bacillus amyloliquefaciens (Aveo; Valent } \\
\text { U.S.A. Corporation) }\end{array}$ & $\ldots$ \\
\hline $\begin{array}{l}\text { Ethephon (Ethephon 2SL; Makhteshim } \\
\text { Agan of North American Inc.) }+ \\
\text { fluopyram + clothianidin }+ \text { B. firmus }\end{array}$ & $\ldots$ \\
\hline Fluopyram + clothianidin $+B$. firmus & $\ldots$ \\
\hline $\begin{array}{l}\text { Tetraconazole (Domark } 230 \text { ME; Gowan } \\
\text { Company) }\end{array}$ & $\ldots$ \\
\hline $\begin{array}{l}\text { Saponins extract of Chenopodium quinoa } \\
\text { (Heads Up) }\end{array}$ & $\cdots$ \\
\hline Untreated check & $\ldots$ \\
\hline
\end{tabular}

a Supplier locations: Bayer CropScience, Research Triangle Park, NC, U.S.A.; BASF, Research Triangle Park, NC, U.S.A.; Syngenta Crop Protection LLC, Greensboro, NC, U.S.A.; Greenspire Global Inc., Des Moines, IA, U.S.A.; Cheminova Inc., Research Triangle Park, NC, U.S.A.; Valent U.S.A. Corporation, Walnut Creek, CA, U.S.A.; Heads Up Plant Protectants, Inc., Saskatchewan, Canada; Makhteshim Agan of North American Inc., Raleigh, NC, U.S.A.; and Gowan Company, Yuma, AZ, U.S.A. 
Disease data were collected at R5 to R6.5 soybean growth stages (Fehr et al. 1971) in all of the trial locations using the same standard scale published (Gibson et al. 1994; Kandel et al. 2015). Briefly, foliar disease incidence (DI) was estimated on the center two rows of each plot as percentage of SDS-symptomatic plants. Disease severity (DS) was estimated on those same symptomatic plants on a 1-to-9 scale based on leaf area covered by chlorotic or necrotic lesions and premature plant death $(1=1$ to $10 \%$ leaf chlorotic or 1 to $5 \%$ leaf necrotic and $9=$ premature plant death). Foliar disease index $(\mathrm{FDX})$ was calculated using the DI and DS as FDX = $\mathrm{FDI} \times \mathrm{FDS} / 9$.

FDX and yield relationship. Effect sizes. Foliar symptoms were observed in most of the studies but severity level was different across the locations and years. Individual plot level FDX ranged from 0 to $100 \%$. In the meta-analysis, the outcome measure is denoted as an effect size. To determine the relationship between SDS and yield, we used three effect sizes (correlation coefficient, intercept, and slope from a regression model), which are the most widely used effect sizes in plant pathology, to explain the relationship between the measure of DS and yield (Dalla Lana et al. 2015; Madden and Paul 2011; Ngugi et al. 2011). The first effect size subjected to meta-analysis was Pearson's correlation coefficient $(r)$, which is used to determine the strength of relationship. The correlation coefficients were determined individually for each of the studies using the PROC CORR procedure in SAS (version 9.4; SAS Institute Inc., Cary, NC, U.S.A.). Pearson's $r$ was then transformed to Fisher's $Z r$ using the following equation, as described previously (Dalla Lana et al. 2015; Madden and Paul 2011):

$$
Z_{k}=1 / 2 \log \left[\left(1+r_{k}\right) /\left(1-r_{k}\right)\right]
$$

where $Z_{k}$ is the Fisher's transformation of the correlation coefficients of the $k^{\text {th }}$ study $(k=1,2, \ldots, n)$ and $r_{k}$ is the Pearson's $r$ of the $k^{\text {th }}$ study. The sampling variance for each study is derived by using the following formula:

$$
v_{z}=\left[1 /\left(n_{k}-3\right)\right]
$$

where $n_{k}$ is the number of pairs of FDX and yield observations in each study. The other two effect sizes used in the meta-analysis were intercepts and slopes of the linear regression equation determined for FDX and yield relationships estimated for each of the 52 studies, after excluding those that did not have disease or yield data. The regression equation was obtained using a mixed model using the PROC GLIMMIX procedure in SAS. Replication was treated as random factor in the model:

$$
y_{k}=\beta_{0}+\beta_{1} x_{k}+\varepsilon
$$

Where $y$ is the yield of the of the $k^{\text {th }}$ study $(k=1,2, \ldots, n), x_{k}$ is the FDX of the $k^{\text {th }}$ study, $\beta_{0}$ is an intercept, $\beta_{1}$ is a slope, and $\varepsilon$ is the random error associated with each study. Normal distribution was assumed for the residuals. The intercept represents the estimated attainable yield in the absence of FDX. The slope denotes the amount of change in yield (kilograms per hectare) per unit (percent) change in FDX. The standard error of the intercepts and slopes was squared to calculate the sampling variances. The weight in the meta-analysis models was calculated as the inverse of the sampling variances.

Meta-analysis models. Standard univariate and bivariate randomeffect meta-analyses were performed to estimate the expected effect sizes and variability among the studies. A univariate random-effect meta-analysis was used for all three response variables and a bivariate random-effect meta-analysis was used for intercept and slope because the two outcomes (slope and intercept) were estimated in the same study (Van Houwelingen et al. 1993). The magnitude of the expected effect size of the intercept and slope from univariate and bivariate random-effect models were similar; thus, the results were presented only from univariate random-effect analysis, as was done in a previous study (Dalla Lana et al. 2015). Random-effect metaanalyses models were fitted in PROC GLIMMIX in SAS, with study considered to be the random effect.
Study heterogeneity and moderator variables. We assessed whether the among-study variance was significantly different from 0 using a likelihood-ratio test statistic, as described elsewhere (Madden and Paul 2011; Paul et al. 2011). We also estimated the $I^{2}$ index, which is a ratio of true heterogeneity to the total observation, that measures the extent of variability in the effect sizes among the studies (Higgins and Thompson 2002) in addition to the likelihood-ratio test. The likelihood-ratio test and the $I^{2}$ both indicated that study heterogeneity exists. Thus, to explain whether and how much they could explain the heterogeneity, location- and study-specific moderator variables were used in the mixed-effect model, where study was used as a random effect and all of the moderator variables were used as fixed effects. All of the moderator variables were specified as categorical, as described below.

Meta-analysis was performed separately for correlation coefficient and regression parameters using a univariate approach, meaning separate mixed effect models were fitted for each of the effect sizes and one moderator variable was included at a time (Paul et al. 2011). This tested whether a moderator influenced the expected effect size and provided an estimate of the expected effect size within each categorical variable. The percent variability explained by each moderator variable was estimated using the following formula:

$$
\text { Percent variability }=100 \times(v-m) / v
$$

where $v$ is among-study variance when the moderator variable was not specified, and $m$ is the variance after the moderator variable was specified.

Moderator variables used in this analysis were disease level, cultivar susceptibility, date of planting, geographic location, and growing season. Studies were grouped into two categories based on disease level in control plots using the following rules: low disease where FDX $>0$ but $<10$ and high disease where FDX $\geq 10$. A $10 \%$ FDX was used as the threshold value to distinguish low and high disease levels because this cutoff point has been successfully used in previous studies (Kandel et al. 2016a, 2018), corresponding to when foliar symptoms are clearly observed in field. Studies were categorized into two groups (susceptible and partially resistant) based on the cultivar susceptibility ratings provided by the suppliers. Based on the planting date reported on the data, studies were categorized into three levels: early $=$ prior to 7 May, conventional $=7$ to 21 May, and late $=$ after 21 May. Growing season and growing state or province were also used as moderator variables to test their influence on the relationship.

Relative yield loss. The damage due to the disease is usually expressed in a relative term as percentage of yield; therefore, the percent yield reduction was also calculated by using the estimates of $\beta_{0}$ and $\beta_{1}$ calculated by meta-analytic random models. The $\beta_{0}$ represents the maximum attainable yield in the absence of disease and $\beta_{1}$ is the rate of change in yield (kilograms per hectare) per unit change (percent) in FDX. The percent yield loss was estimated by dividing the slope by intercept and multiplying by 100 , as follows:

$$
\text { Percent yield loss }=\left(\beta_{1} / \beta_{0}\right) \times 100
$$

\section{Results}

Primary correlation and regression analyses. The correlations in primary analyses showed that SDS and yield were negatively correlated in most of the studies. The coefficients $(r)$ ranged from -0.91 to 0.28 , and $85 \%$ of the studies had negative $r$. The distribution of $r$, as shown by the histogram, was slightly skewed toward negative (Fig. 1A); however, after the transformation of $r$, Fisher's transformed $r$ (Fisher's $Z r$ ) was more symmetrical toward the mean (Fig. 1B), which justifies the transformation of $r$ for further meta-analysis.

The linear regression between the SDS and yield showed that slope $\left(\beta_{1}\right)$, the rate of change in yield per unit change in FDX, was negative in most of the studies, suggesting that yield decreases with increasing disease. The intercept $\left(\beta_{0}\right)$, the attainable yield in absence of disease, ranged from 2,548 to $5,723 \mathrm{~kg} / \mathrm{ha}$ (Fig. 1C). The distribution of $\beta_{1}$ ranged from -222.0 to $64.6 \mathrm{~kg} / \mathrm{ha}$, with negative values in nearly $85 \%$ of the studies (Figs. 1D and 2). 
Meta-analysis of the correlation and regression parameters. The overall mean Fisher's $Z r\left(\bar{Z}_{r}\right)$ estimated by a random-effect meta-analysis, was -0.41 (95\% confidence interval $[\mathrm{CI}]=-0.51$ to -0.30) (Table 2). The corresponding back-transformed $r(\bar{r})$ was -0.39 (95\% CI $=-0.47$ to -0.29$)$. The standard test statistics from the meta-analysis showed that the $\bar{Z}_{r}$ was statistically different from zero, suggesting a strong negative relationship between FDX and yield (Table 2). The estimated $\bar{\beta}_{O}$ and $\bar{\beta}_{l}$ and their statistics are given in Table 2. Briefly, the mean attainable yield in the absence of SDS was estimated to be $4,130 \mathrm{~kg} / \mathrm{ha}$. The $95 \% \mathrm{CI}$ around $\bar{\beta}_{O}$ was 3,922 to $4,339 \mathrm{~kg} / \mathrm{ha}$. For every unit increase in FDX, there was an average reduction in yield of $21 \mathrm{~kg} / \mathrm{ha}(95 \% \mathrm{CI}=-26.4$ to -15.4$)$ (Table 2).

Study heterogeneity and moderator variables. The variation in correlation coefficients from individual studies is shown in Figure 1 and in regression parameters is shown in Figure 2. The estimated amongstudy variances for $\bar{Z}_{r}\left(\sigma_{Z}^{2}=0.107\right), \bar{\beta}_{O}\left(\sigma_{\beta 0}^{2}=527,064\right)$, and $\bar{\beta}_{1}\left(\sigma_{\beta 1}^{2}=236\right)$ were statistically different from zero $(P<0.001)$. This is based on the likelihood-ratio test, which rejects the null hypothesis that the studies were homogenous, indicating that there was a considerable impact of among-study variance in this dataset. The high $I^{2}$ also suggest high levels of heterogeneity, which were only partially explained by moderator variables.

All moderator variables (disease level, cultivar susceptibility, planting date, study location, and year) were tested individually as a categorical variable in the mixed-effect models. Effect of the moderator, among-study variance after the moderator used, and the variability explained by the moderator variables are depicted in Table 3 . The variability explained by moderator variables was low.
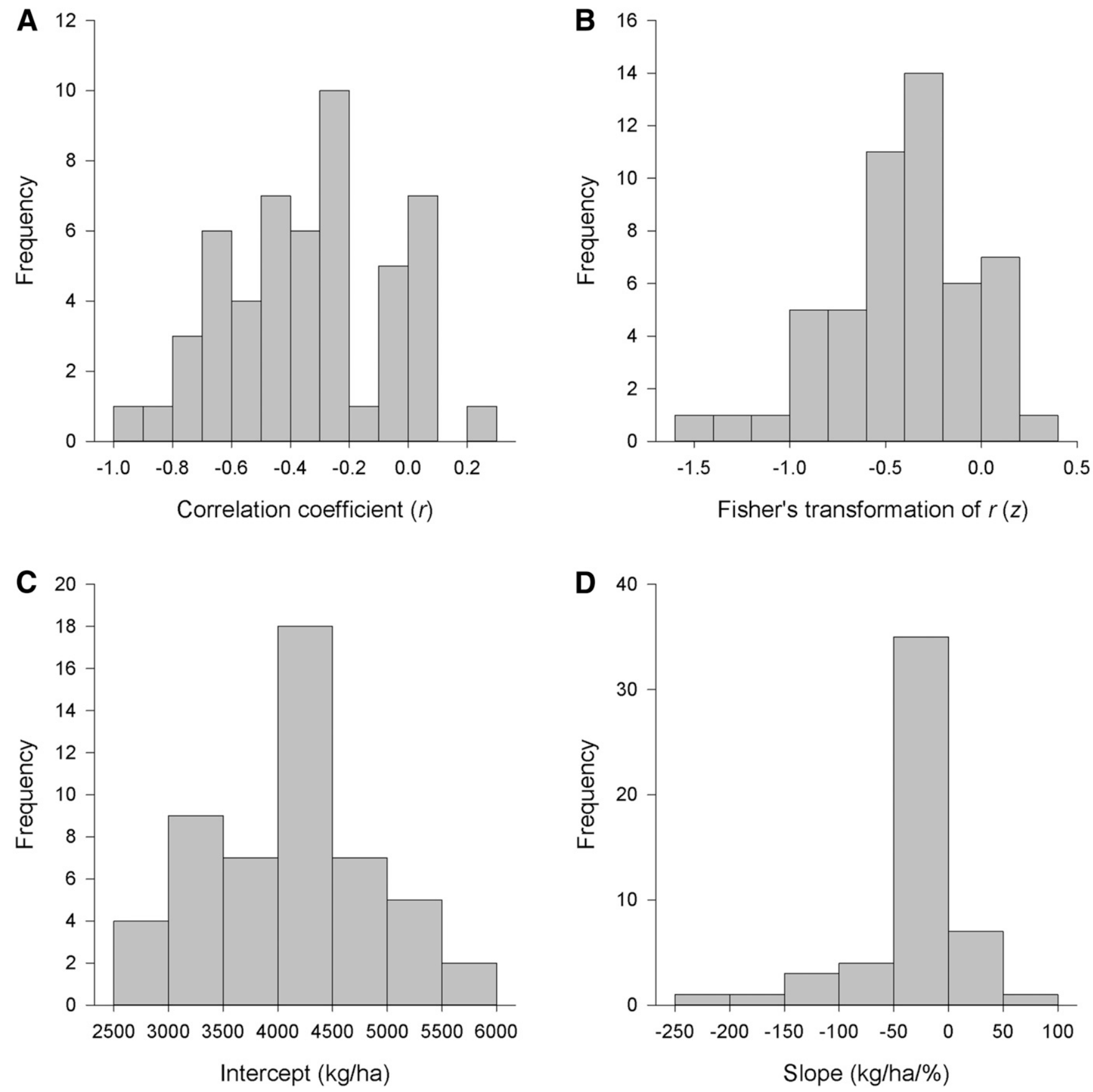

Fig. 1. Frequency distribution of $\mathbf{A}$, correlation coefficient $(r)$ and $\mathbf{B}$, Fisher's transformed correlation coefficient (Fisher's $Z r)$ and linear regression parameters $\mathbf{C}$, intercept $\left(\beta_{0}\right)$ and D, slope $\left(\beta_{1}\right)$ for the relationship between sudden death syndrome foliar index and soybean yield estimated in individual studies. 
The disease level and cultivar susceptibility had a significant effect on $\bar{Z}_{r}$ but not on the regression parameters (Table 3 ). The variability explained by disease level was $27 \%$ and by cultivar susceptibility was $11 \%$. In considering base disease level as the moderator, a stronger correlation was observed between FDX and yield when

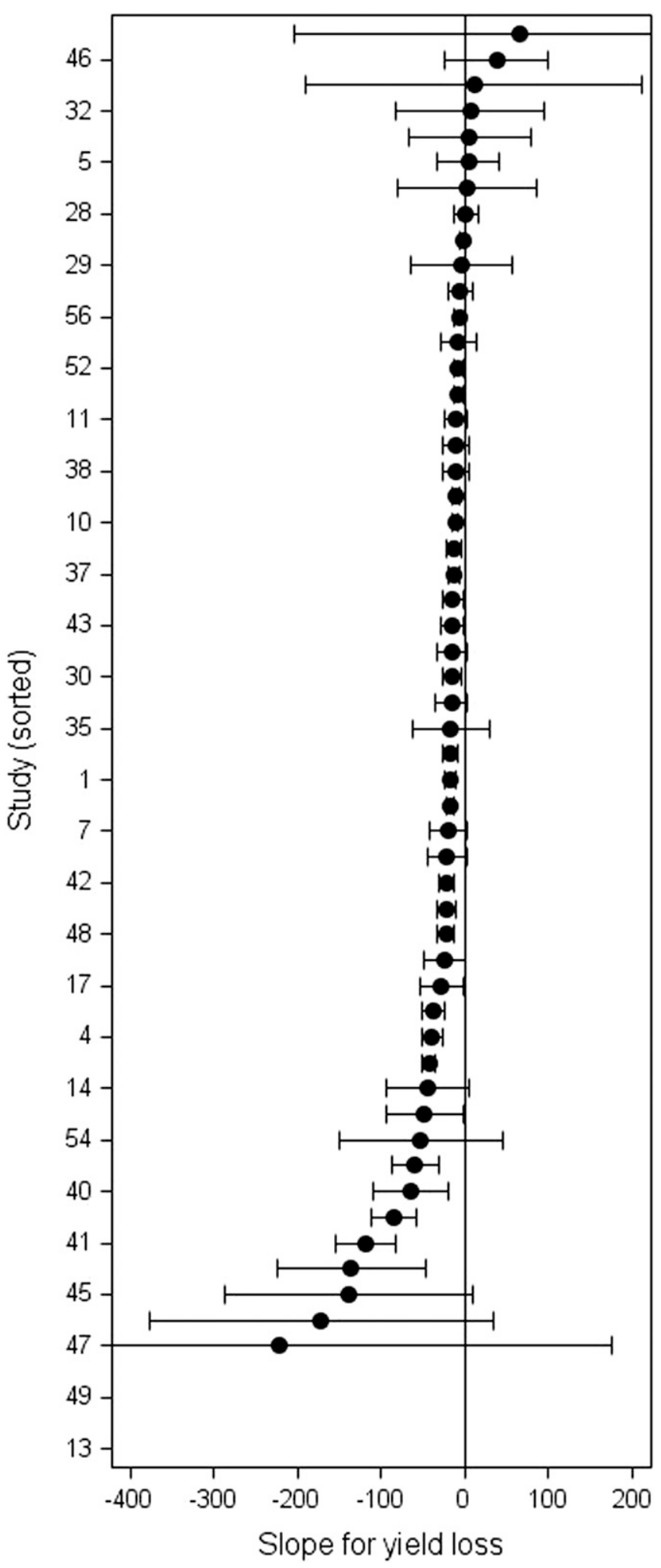

Fig. 2. Forest plot showing the distribution of the regression coefficient slope $\left(\beta_{1}\right)$ estimated in individual studies (sorted from low to high) for the relationship between sudden death syndrome foliar index and soybean yield. Black circles represent the magnitude of $\beta_{1}(\mathrm{~kg} / \mathrm{ha} / \%)$ in each individual study and horizontal bars indicate the lower and upper $95 \%$ confidence interval limits. disease was high (FDX $>10 \% ; \bar{Z}_{r}=-0.59 ; 95 \% \mathrm{CI}=-0.73$ to -0.46$)$ compared with when disease was low $\left(\bar{Z}_{r}=-0.25 ; 95 \%\right.$ $\mathrm{CI}=-0.38$ to -0.13$)$. Similarly, a higher $r$ was observed for susceptible cultivars $\left(\bar{Z}_{r}=-0.52 ; 95 \% \mathrm{CI}=-0.65\right.$ to -0.38$)$ compared with partially resistant cultivars $\left(\bar{Z}_{r}=-0.29 ; 95 \% \mathrm{CI}=-0.43\right.$ to -0.15$)$ (Table 4). The $\bar{r}$ with lower and upper limit at $95 \%$ CI for all moderator variables is depicted in Figure 3. Date of planting did not influence any expected effect size examined here. The influence of study location and year was significant for $\bar{\beta}_{O}$ but not for the other expected effect sizes. The magnitude of $\bar{\beta}_{O}$ varied among the locations, with Indiana and Ontario having the largest attainable yield and Michigan having the lowest (Table 4). The $\bar{\beta}_{O}$ was highest in 2016 and lowest in 2015 (Table 4 ). The study location explained $22 \%$ of the variability across studies while growing season explained $31 \%$ of the variability across the studies for $\bar{\beta}_{O}$ (Tables 3 and 4 ). Although none of moderator variables significantly influenced the magnitude of $\bar{\beta}_{1}$, overall mean slope was always negative for all categories of the moderator variables tested (Tables 3 and 4).

Relative yield loss. The relative damage coefficient was estimated to be $0.51 \%$ for each percent increase in FDX using the mean intercept and slopes estimated from the random-effect meta-analytic model. In other words, the average reduction of the attainable yield is expected to be $51 \%$ when there is maximum observed disease $(\mathrm{FDX}=100 \%)$ at R5/R6. The moderator variables were not significant for $\bar{\beta}_{1}$; therefore, percent yield loss was not estimated for the moderator variables

\section{Discussion}

SDS is well known to cause significant reductions in soybean yield. This is the first study where numerous site-years of data were analyzed using meta-analytic methods instead of utilizing traditional yield loss studies. Using this approach, we found that SDS foliar symptoms and yield were negatively correlated.

A significant negative slope obtained through random-effect meta-analytic models confirmed the negative linear relationship between SDS and soybean yield. Negative linear relationships between the measure of SDS severity and yield have been previously reported (Gibson et al. 1994; Luo et al. 2000; Njiti et al. 1998 b) but results were inconsistent. From our study, we calculated that, for each unit increase in FDX, yield declined $0.51 \%$. An example of using this relationship is as follows. A field with an expected yield of $4,130 \mathrm{~kg} / \mathrm{ha}$ (intercept) and an FDX of 10 could experience a yield reduction of over $200 \mathrm{~kg} / \mathrm{ha}$. Similar to our results, Luo et al. (2000) estimated a yield loss of 18 to $29 \mathrm{~kg} / \mathrm{ha}$ per unit increase in FDX from a single-row plot experiment conducted for 2 years in 1997 and 1998 in Illinois. However, Gibson et al. (1994) reported a much broader range of yield loss ( 7 to $34 \mathrm{~kg} / \mathrm{ha}$ ) per unit increase in SDS incidence. Njiti et al. (1998b) estimated yield loss to be $18 \%$ on individual plants and $12 \%$ on whole plots for each unit increase in foliar SDS severity, which was greater than the effect size estimated in our study, although FDX was used in the analysis in our study instead of DS. The estimates in Njiti et al. (1998b) were greater than our study and may be due to the difference in disease levels.

In general, our results corroborated those studies, which reported negative association between SDS severity and yield (de Farias Neto et al. 2006; Kandel et al. 2016a; Luo et al. 2000; Marburger et al. 2016; Njiti et al. 1998b; Roy et al. 1997; Rupe et al. 1993, 1997; Sjarpe et al. in press). However, some studies also reported no relationship between the root colonization, foliar symptoms, and yield (Scherm and Yang 1996; Stephens et al. 1993). Hershman et al. (1990) reported that moderate to severe SDS symptom levels reduced yield but mild SDS symptom levels did not influence yield. The inconsistency might be related to the differences in disease appearance time, level of overall disease, cultivar susceptibility to SDS, and soil and weather conditions (Hartman et al. 2015b; Rupe 1989; Stephens et al. 1993).

In the analyses presented here, the amount of variation explained by moderators was relatively low. Cultivar susceptibility and disease 
Table 2. Expected effect sizes, their related statistics, and heterogeneity measurements for the relationship between sudden death syndrome foliar index and soybean yield based on random-effect meta-analyses

\begin{tabular}{|c|c|c|c|c|c|c|c|c|c|}
\hline \multirow[b]{2}{*}{ Response } & \multirow[b]{2}{*}{$K^{c}$} & \multirow[b]{2}{*}{ Size } & \multicolumn{4}{|c|}{ Statistics $^{\mathbf{a}}$} & \multicolumn{3}{|c|}{ Heterogeneity $^{\mathbf{b}}$} \\
\hline & & & SE & $\mathbf{C I}_{L}$ & $\mathbf{C I}_{\boldsymbol{U}}$ & $P$ value & $\sigma^{2}$ & $P$ value & $I^{2}$ \\
\hline \multicolumn{10}{|l|}{ Correlation coefficients } \\
\hline Transformed correlation (Fisher's $\bar{Z}_{r}$ ) & 52 & -0.41 & 0.05 & -0.51 & -0.30 & $<0.001$ & 0.107 & $<0.001$ & 78.9 \\
\hline Correlation coefficient $(\bar{r})$ & 52 & -0.39 & 0.05 & -0.47 & -0.29 & $\ldots$ & $\ldots$ & $\ldots$ & $\ldots$ \\
\hline \multicolumn{10}{|l|}{ Regression parameters } \\
\hline Intercept $\left(\bar{\beta}_{0}\right)$ & 52 & 4,130 & 104 & 3,922 & 4,339 & $<0.001$ & 527,064 & $<0.001$ & 96.9 \\
\hline Slope $\left(\bar{\beta}_{1}\right)$ & 52 & 20.9 & 2.7 & -26.4 & -15.4 & $<0.001$ & 236.0 & $<0.001$ & 80.0 \\
\hline
\end{tabular}

a Abbreviations: $\mathrm{SE}=$ standard error of the effect size, $\mathrm{CI}_{L}=$ lower limit and $\mathrm{CI}_{U}=$ upper limit of $95 \%$ confidence interval of the expected effect sizes, and $P$ value $=$ probability of rejecting null hypothesis that the effect size is not statistically different from zero.

b Abbreviations: $\sigma^{2}=$ among-study variability estimates, $P$ value $=$ probability of rejecting null hypothesis that studies were homogenous, and $I^{2}=$ the measure of variability in the expected effect sizes.

c Total number of studies used in each analysis.

Table 3. Influence of moderator variables on transformed correlation coefficients and regression parameters for the relationship between sudden death syndrome foliar index (FDX) and soybean yield based on separate mixed effect meta-analyses

\begin{tabular}{|c|c|c|c|c|c|c|c|c|c|}
\hline \multirow[b]{2}{*}{ Variables $^{\mathbf{a}}$} & \multicolumn{3}{|c|}{$\begin{array}{c}\text { Transformed correlation } \\
\left(\text { Fisher's } \bar{Z}_{\boldsymbol{r}}\right)\end{array}$} & \multicolumn{3}{|c|}{ Intercept $\left(\bar{\beta}_{0}\right)$} & \multicolumn{3}{|c|}{ Slope $\left(\bar{\beta}_{1}\right)$} \\
\hline & $P$ value $^{b}$ & Study $^{c}$ & $\operatorname{Expl}^{d}$ & $P$ value & Study & Expl & $P$ value & Study & Expl \\
\hline Disease level & 0.000 & 0.0781 & 26.9 & 0.179 & 462,699 & 12.2 & 0.242 & 241.7 & -2.4 \\
\hline Cultivar resistance & 0.020 & 0.0949 & 11.2 & 0.596 & 470,116 & 10.8 & 0.588 & 250.2 & -6.0 \\
\hline Date of planting & 0.844 & 0.1116 & -4.5 & 0.165 & 460,876 & 12.6 & 0.579 & 253.8 & -7.6 \\
\hline Study location & 0.964 & 0.1184 & -10.9 & 0.020 & 409,264 & 22.4 & 0.227 & 212.9 & 9.8 \\
\hline Growing season & 0.218 & 0.1030 & 3.6 & 0.000 & 365,850 & 30.6 & 0.628 & 292.9 & -24.1 \\
\hline
\end{tabular}

a Moderator variables included in the mixed effect meta-analysis as categorical variables. Disease level = low (FDX $>0$ but $<10$ ) and high (FDX $\geq 10$ ); Cultivar susceptibility = susceptible and partially resistant; and Date of planting = early (prior to 7 May), conventional (7 to 21 May), and late (after 21 May). Growing season and study location (state or province) were also used as moderator variables to test their influence on the relationship.

b $P$ value $=$ probability of rejecting the null hypothesis that the expected effect size is not influenced by the moderator variable.

c Among-study variance after including the moderator variable.

d Variability explained by each moderator variable calculated as $100 \times(v-m) / v$, where $v$ is among-study variance when the moderator variable was not specified and $m$ is the variance after the moderator variable is specified.

Table 4. Expected effect sizes and related statistics of moderator variable categories for transformed correlation coefficient and regression parameters for the relationship between sudden death syndrome foliar index and soybean yield based on separate mixed effect meta-analyses ${ }^{\mathrm{a}}$

\begin{tabular}{|c|c|c|c|c|c|c|c|c|c|c|c|c|c|}
\hline \multirow[b]{2}{*}{ Variables $^{b}$} & \multirow[b]{2}{*}{$K^{\mathbf{c}}$} & \multicolumn{4}{|c|}{$\begin{array}{c}\text { Transformed Correlation } \\
\text { (Fisher's } \bar{Z}_{\boldsymbol{r}} \text { ) }\end{array}$} & \multicolumn{4}{|c|}{ Intercept $\left(\bar{\beta}_{0}\right)$} & \multicolumn{4}{|c|}{ Slope $\left(\bar{\beta}_{1}\right)$} \\
\hline & & Size & SE & $\mathrm{CI}_{L}$ & $\mathrm{CI}_{U}$ & Size & SE & $\mathrm{CI}_{L}$ & $\mathbf{C I}_{U}$ & Size & SE & $\mathbf{C I}_{L}$ & $\mathbf{C I}_{U}$ \\
\hline \multicolumn{14}{|l|}{ Disease level } \\
\hline Low & 29 & -0.254 & 0.06 & -0.38 & -0.13 & 4,248 & 130 & 2,597 & 5,899 & -25.3 & 4.7 & -34.8 & -15.8 \\
\hline High & 23 & -0.596 & 0.07 & -0.73 & -0.46 & 3,983 & 148 & 2,101 & 5,864 & -18.5 & 3.4 & -25.8 & -11.3 \\
\hline \multicolumn{14}{|l|}{ Cultivar } \\
\hline Resistant & 25 & -0.288 & 0.07 & -0.43 & -0.15 & 4,185 & 141 & 2,398 & 5,972 & -22.9 & 4.5 & -32.2 & -13.6 \\
\hline Susceptible & 27 & -0.516 & 0.07 & -0.65 & -0.38 & 4,081 & 138 & 2,331 & 5,831 & -19.8 & 3.6 & -27.3 & -12.3 \\
\hline \multicolumn{14}{|l|}{ Planting date } \\
\hline Early & 19 & -0.437 & 0.09 & -0.61 & -0.26 & 3,902 & 160 & 1,869 & 5,936 & -22.0 & 4.7 & -31.7 & -12.2 \\
\hline Conven & 15 & -0.362 & 0.10 & -0.56 & -0.17 & 4,191 & 184 & 1,851 & 6,531 & -16.0 & 5.7 & -27.9 & -4.0 \\
\hline Late & 18 & -0.410 & 0.09 & -0.59 & -0.23 & 4,330 & 165 & 2,232 & 6,428 & -23.3 & 4.6 & -32.8 & -13.9 \\
\hline \multicolumn{14}{|l|}{ Location } \\
\hline Iowa & 14 & -0.465 & 0.10 & -0.67 & -0.26 & 4,066 & 178 & 1,805 & 6,327 & -19.0 & 5.1 & -30.1 & -8.0 \\
\hline Illinois & 5 & -0.437 & 0.17 & -0.78 & -0.09 & 4,269 & 289 & 594 & 7,943 & -14.7 & 7.6 & -31.6 & 2.2 \\
\hline Indiana & 6 & -0.325 & 0.16 & -0.65 & 0.00 & 4,417 & 268 & 1,017 & 7,817 & -15.9 & 7.9 & -32.6 & 0.8 \\
\hline Michigan & 10 & -0.437 & 0.12 & -0.68 & -0.19 & 3,507 & 213 & 807 & 6,208 & -22.1 & 5.6 & -34.3 & -9.9 \\
\hline Ontario & 15 & -0.355 & 0.10 & -0.56 & -0.15 & 4,445 & 174 & 2,240 & 6,651 & -31.5 & 5.7 & -43.4 & -19.7 \\
\hline Wisconsin & 2 & -0.360 & 0.27 & -0.91 & 0.19 & 4,167 & 462 & $-1,705$ & 10,038 & -5.5 & 10.5 & -29.1 & 18.1 \\
\hline \multicolumn{14}{|l|}{ Season } \\
\hline 2013 & 8 & -0.451 & 0.12 & -0.70 & -0.20 & 3,913 & 219 & 1,132 & 6,695 & -19.2 & 6.7 & -33.3 & -5.1 \\
\hline 2014 & 11 & -0.529 & 0.11 & -0.75 & -0.31 & 3,940 & 191 & 1,519 & 6,361 & -24.2 & 6.1 & -36.8 & -11.5 \\
\hline 2015 & 13 & -0.231 & 0.10 & -0.43 & -0.03 & 3,876 & 179 & 1,607 & 6,145 & -12.9 & 6.8 & -27.0 & 1.3 \\
\hline 2016 & 10 & -0.533 & 0.12 & -0.77 & -0.30 & 4,968 & 198 & 2,454 & 7,482 & -27.0 & 6.6 & -40.7 & -13.3 \\
\hline 2017 & 10 & -0.339 & 0.11 & -0.57 & -0.11 & 4,013 & 200 & 1,476 & 6,550 & -22.0 & 7.5 & -37.7 & -6.3 \\
\hline
\end{tabular}

a $\mathrm{SE}=$ standard error of the effect size and $\mathrm{CI}_{L}=$ lower limit and $\mathrm{CI}_{U}=$ upper limit of $95 \%$ confidence interval of the expected effect sizes.

b Moderator variables included in the mixed effect meta-analysis as categorical variables. Disease level $=$ low (FDX $>0$ but $<10)$ and high (FDX $\geq 10)$; Cultivar susceptibility = susceptible and partially resistant; and Planting date = early (prior to 7 May), conventional (Conven; 7 to 21 May), and late (after 21 May). Growing season and study location (state or province) were also used as moderator variables to test their influence on the relationship.

c Total number of studies used in each analysis. 


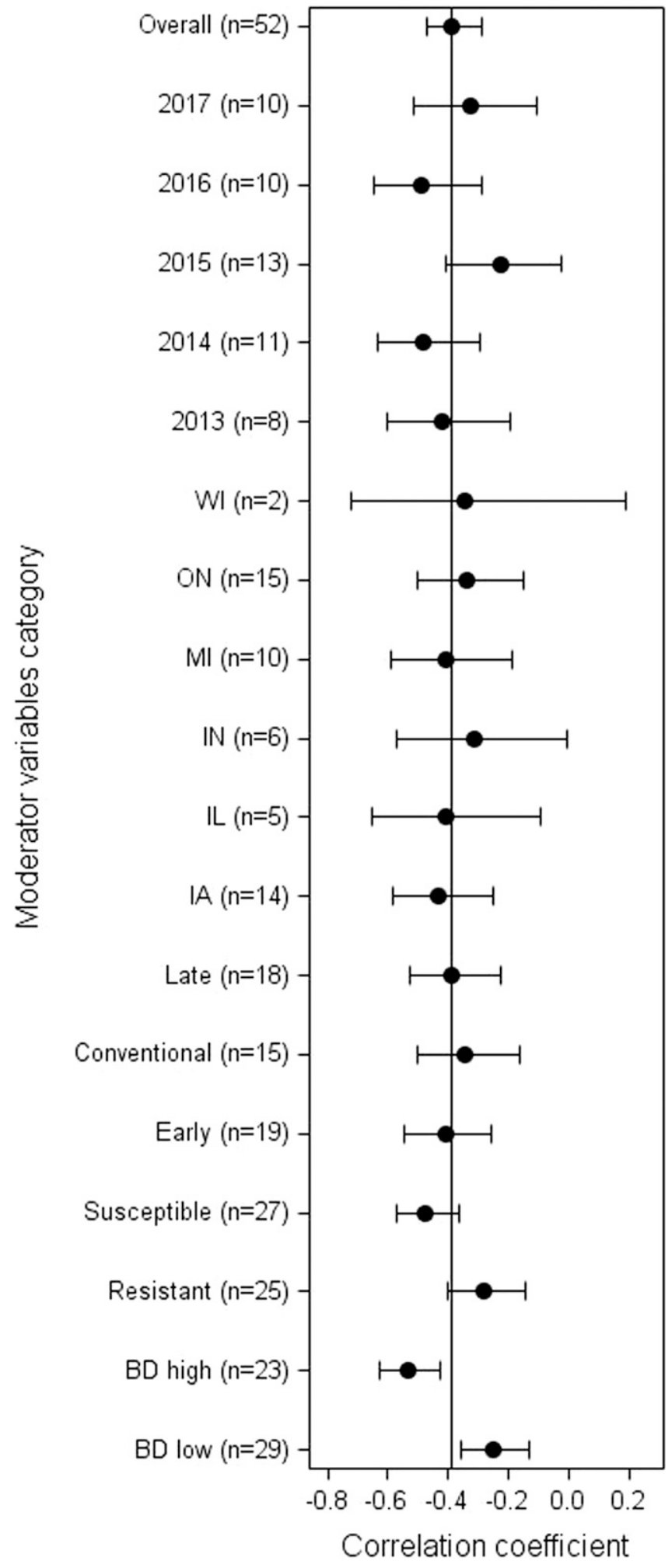

Fig. 3. Back-transformed correlation coefficient from Fisher's transformed correlation coefficient for the relationship between sudden death syndrome foliar index and soybean yield. The vertical line in the middle represents the overall mean effect size. Black circles represent the expected effect size for each moderator variable shown, while the horizontal line going through the black circle represents the lower and upper 95\% confidence interval limits. Moderator variables included in the mixed-effect meta-analysis as categorical variables were base disease level $(\mathrm{BD})=$ low (foliar disease index $[\mathrm{FDX}]>0$ but $<10$ ) and high (FDX $\geq 10$ ); cultivar susceptibility = susceptible and resistant; date of planting = early (prior to 7 May), conventional (7 to 21 May), and late (after 21 May); growing season $=2013$ to 2017; and study location = lowa (IA), Illinois (IL), Indiana (IN), Michigan (MI), Ontario (ON), and Wisconsin (WI). The number of studies used in the analysis of the respective moderator variables is shown in parentheses. level influenced the correlation coefficients significantly. Stronger correlation between FDX and yield was observed for studies with more SDS than the studies with less disease. Similarly, greater magnitude of the correlation coefficient was observed with susceptible cultivars than with resistant cultivars. Resistant cultivars had lower FDX and produced higher yields, which was also observed in other studies (Kandel et al. 2016a, 2018, 2019; Sjarpe et al. in press). However, the fact that slope was not influenced by the cultivar level means that susceptible and partially resistant cultivars will experience yield loss at a similar rate of FDX increase. This has been reported previously when detectable yield loss was reported, even in resistant cultivars (Kandel et al. 2016a, 2018). Njiti et al. (1998b) also reported similar direction and magnitude of regression coefficients among and within the genotypes evaluated in different environments.

Growing season did not influence the correlation and slope but did influence the intercept and showed that yield potential in 2016 was greater than in other years in this study. Many of the locations in this study were supplemented by irrigation; therefore, we did not use precipitation as a separate variable. However, several previous studies have already explained the role of precipitation in SDS incidence and severity (Kandel et al. 2016b; Leandro et al. 2013). SDS is considered to be a disease of high-yielding environments because the environment that favors soybean growth also favors SDS development (Roy et al. 1997). Although it was not very surprising, geographic locations, likely due to the differences in soil properties, climate, and management factors, influenced the intercept and explained $22 \%$ of the variability observed in this analysis.

Changing agricultural practices such as early planting aimed at improving yields have been reported to influence DS and yield response to seed treatment (Hershman et al. 1990; Kandel et al. 2018; Marburger et al. 2016; Vosberg et al. 2017) but we found that planting date did not influence any of the expected effect sizes. In a previous study, Marburger et al. (2016) reported that greater yield loss was observed in early plantings versus late plantings. In another study, yield response to fluopyram seed treatment was greater in early-planted soybean than late-planted soybean, perhaps due to high yield potential in early-planted soybean (Vosberg et al. 2017). Early-planted soybean plants have greater chances of being exposed to wet and cool soil for longer periods of time compared with late-planted soybean. Longer exposure to these conditions promotes root infection by $F$. virguliforme. Despite this issue, several previous reports have shown that late-planted soybean produce less yield because of premature flowering and short sunlight duration regardless of the disease level in the field (Kandel et al. 2016b; Marburger et al. 2016).

The meta-analysis presented here shows that yield loss can occur even when SDS levels are low; however, our studies only measured foliar DS and did not examine root rot. Under certain conditions when environment is not conducive for movement of toxins or development of foliar symptoms during the reproductive stages, root rot will still reduce the root's ability to acquire water and nutrients from the soil and may cause some yield loss (Sjarpe et al. in press). Wang et al. (2019) identified similar levels of $F$. virguliforme DNA accumulation in soybean roots between cultivars that expressed heavy and low FDX.

Through this meta-analysis, we were able to estimate the overall relationship between SDS foliar symptoms and yield as well as identify specific variables that explain portions of the variability in correlation coefficients and intercepts; however, major portions of the variability remain unexplained. This might be due to some unknown factors associated with the studies such as cultivar susceptibility to other diseases, pests and abiotic stresses, genetic yield potential of the cultivars, interaction of $F$. virguliforme with other soil microbes, and so on. The influence of disease onset time, which was discussed earlier, may have contributed, at least in part, to the variability as well. It is important to test how disease onset time effects the SDS-yield relationship in future experiments. The relationships reported here serve as a foundation to estimate yield loss due to SDS in small- and large-scale situations in the future. This information will not only help farmers make management decisions but also help other researchers, crop insurance agencies, and government policy makers determine the impact of SDS on soybean. 


\section{Acknowledgments}

We thank Bayer CropScience, Heads Up Plant Protectants, Inc., Syngenta Crop Protection LLC., Cheminova, Inc., and Greenspire Global, Inc. for providing their products to test in this study; and K. Ames, J. Pike, and J. Weems from Illinois, N. Anderson and J. Ravellette from Indiana, S. Wiggs, C. Hunt, and D. Sjarpe from Iowa, A. M. Byrne and J. F. Boyse from Michigan, N. Braun and P. Okello from South Dakota, S. Chapman and B. Mueller from Wisconsin, and C. Van Herk, G. Kotulak, and B. Jones from Ontario for their assistance with the field studies.

\section{Literature Cited}

Allen, T. W., Bradley, C. A., Sisson, A. J., Byamukama, E., Chilvers, M. I., Coker, C. M., Collins, A. A., Damicone, J. P., Dorrance, A. E., Dufault, N. S., Esker, P. D., Faske, T. R., Giesler, L. J., Grybauskas, A. P., Hershman, D. E., Hollier, C. A., Isakeit, T., Jardine, D. J., Kemerait, R. C., Kleczewski, N. M., Koenning, S. R., Kurle, J. E., Malvick, D. K., Markell, S. G., Mehl, H. L., Mueller, D. S., Mueller, J. D., Mulrooney, R. P., Nelson, B. D., Newman, M. A., Osborne, L., Overstreet, C., Padgett, G. B., Phipps, P. M., Price, P. P., Sikora, E. J., Smith, D. L., Spurlock, T. N., Tande, C. A., Tenuta, A. U., Wise, K. A., Wrather, J. A., and Young-Kelly, H. 2017. Soybean yield loss estimates due to diseases in the United States and Ontario, Canada from 2010 to 2014. Plant Health Prog. 18: 19-27.

Aoki, T., O’Donnell, K., Homma, Y., and Lattanzi, A. R. 2003. Sudden-death syndrome of soybean is caused by two morphologically and phylogenetically distinct species within the Fusarium solani species complex $-F$ virguliforme in North America and F. tucumaniae in South America. Mycologia 95: 660-684.

Brar, H. K., Swaminathan, S., and Bhattacharyya, M. K. 2011. The Fusarium virguliforme toxin FvTox1 causes foliar sudden death syndrome-like symptoms in soybean. Mol. Plant-Microbe Interact. 24:1179-1188.

Dalla Lana, F., Ziegelmann, P. K., Maia, A. H. N., Godoy, C. V., and Del Ponte, E. M. 2015. Meta-analysis of the relationship between crop yield and soybean rust severity. Phytopathology 105:307-315.

de Farias Neto, A. L., Hartman, G. L., Pedersen, W. L., Li, S., Bollero, G. A., and Diers, B. W. 2006. Irrigation and inoculation treatments that increase the severity of soybean sudden death syndrome in the field. Crop Sci. 46:2547-2554.

Fehr, W. R., Caviness, C. E., Burmood, D. T., and Pennington, J. S. 1971. Stage of development descriptions for soybeans, Glycine max (L.) Merrill. Crop Sci. 11:929-931.

Gibson, P., Shenaut, M., Njiti, V., Suttner, R., and Myers, O., Jr. 1994. Soybean varietal response to sudden death syndrome. Pages 20-40 in: Proc. 24th Soybean Seed Res. Conf. Chicago. D. Wilkinson, ed. American Seed Trade Association, Washington, DC, U.S.A.

Gongora-Canul, C., and Leandro, L. 2011. Effect of soil temperature and plant age at time of inoculation on progress of root rot and foliar symptoms of soybean sudden death syndrome. Plant Dis. 95:436-440.

Hartman, G. L., Chang, H. X., and Leandro, L. F. 2015a. Research advances and management of soybean sudden death syndrome. Crop Prot. 73:60-66.

Hartman, G. L., Leandro, L. F. S., and Rupe, J. C. 2015b. Sudden death syndrome. Pages 88-90 in: Compendium of Soybean Disease and Pests. G. L. Hartman, J. C. Rupe, E. F. Sikora, L. L. Domier, J. A. Davis, and K. L. Steffey, eds. American Phytopathological Society, St. Paul, MN, U.S.A.

Hershman, D., Hendrix, J., Stuckey, R., Bachi, P., and Henson, G. 1990. Influence of planting date and cultivar on soybean sudden death syndrome in Kentucky. Plant Dis. 74:761-766.

Higgins, J., and Thompson, S. G. 2002. Quantifying heterogeneity in a metaanalysis. Stat. Med. 21:1539-1558.

Hirrel, M. C. 1983. Sudden death syndrome of soybean-A disease of unknown etiology. Phytopathology 73:501-502.

Jin, H., Hartman, G., Nickell, C., and Widholm, J. 1996. Characterization and purification of a phytotoxin produced by Fusarium solani, the causal agent of soybean sudden death syndrome. Phytopathology 86:277-282.

Kandel, Y. R., Bradley, C. A., Chilvers, M. I., Mathew, F. M., Tenuta, A. U., Smith, D. L., Wise, K. A., and Mueller, D. S. 2019. Effect of seed treatment and foliar crop protection products on sudden death syndrome and yield of soybean. Plant Dis. 103:1712-1720.

Kandel, Y. R., Bradley, C. A., Wise, K. A., Chilvers, M. I., Tenuta, A. U., Davis, V. M., Esker, P. D., Smith, D. L., Licht, M. A., and Mueller, D. S. 2015. Effect of glyphosate application on sudden death syndrome of glyphosate-resistant soybean under field conditions. Plant Dis. 99:347-354.

Kandel, Y. R., McCarville, M., Adee, E. A., Bond, J. P., Chilvers, M. I., Conley, S. P., Giesler, L. J., Kelly, H. M., Malvick, D., Mathew, F. M., Rupe, J. C., Sweets, L., Tenuta, A., Wise, K. A., and Mueller, D. S. 2018. Benefits and profitability of fluopyram-amended seed treatments for suppressing sudden death syndrome and protecting soybean yield: A meta-analysis. Plant Dis. 102:1093-1100.
Kandel, Y. R., Wise, K. A., Bradley, C. A., Chilvers, M. I., Tenuta, A. U., and Mueller, D. S. 2016a. Fungicide and cultivar effects on sudden death syndrome and yield of soybean. Plant Dis. 100:1339-1350.

Kandel, Y. R., Wise, K. A., Bradley, C. A., Tenuta, A. U., and Mueller, D. S. 2016b. Effect of planting date, seed treatment, and cultivar on plant population, sudden death syndrome, and yield of soybean. Plant Dis. 100: $1735-1743$

Leandro, L. F. S., Robertson, A. E., Mueller, D. S., and Yang, X. B. 2013. Climatic and environmental trends observed during epidemic and non-epidemic years of soybean sudden death syndrome in Iowa. Plant Health Prog. 14.

Luo, Y., Hildebrand, K., Chong, S., Myers, O., and Russin, J. 2000. Soybean yield loss to sudden death syndrome in relation to symptom expression and root colonization by Fusarium solani f. sp. glycines. Plant Dis. 84: 914-920.

Madden, L. V., and Paul, P. A. 2011. Meta-analysis for evidence synthesis in plant pathology: An overview. Phytopathology 101:16-30.

Marburger, D. A., Smith, D. L., and Conley, S. P. 2016. Revisiting planting date and cultivar effects on soybean sudden death syndrome development and yield loss. Plant Dis. 100:2152-2157.

Ngugi, H. K., Esker, P. D., and Scherm, H. 2011. Meta-analysis to determine the effects of plant disease management measures: Review and case studies on soybean and apple. Phytopathology 101:31-41.

Njiti, V. N., Doubler, T. W., Suttner, R. J., Gray, L. E., Gibson, P. T., and Lightfoot, D. A. 1998a. Resistance to soybean sudden death syndrome and root colonization by Fusarium solani f. sp. glycines in near-isogenic lines. Crop Sci. 38:472-477.

Njiti, V. N., Shenaut, M. A., Suttner, R. J., Schmidt, M. E., and Gibson, P. T. 1998b. Relationship between soybean sudden death syndrome disease measures and yield components in F6-derived lines. Crop Sci. 38: 673-678.

Paul, P. A., Madden, L. V., Bradley, C. A., Robertson, A. E., Munkvold, G. P., Shaner, G., Wise, K. A., Malvick, D. K., Allen, T. W., Grybauskas, A., Vincelli, P., and Esker, P. D. 2011. Meta-analysis of yield response of hybrid field corn to foliar fungicides in the U.S. Corn Belt. Phytopathology 101: 1122-1132.

Pudake, R. N., Swaminathan, S., Sahu, B. B., Leandro, L. F., and Bhattacharyya, M. K. 2013. Investigation of the Fusarium virguliforme FvTox 1 mutants revealed that the FvTox1 toxin is involved in foliar sudden death syndrome development in soybean. Curr. Genet. 59:107-117.

Roy, K., Hershman, D., Rupe, J., and Abney, T. 1997. Sudden death syndrome of soybean. Plant Dis. 81:1100-1111.

Rupe, J. 1989. Frequency and pathogenicity of Fusarium solani recovered from soybeans with sudden death syndrome. Plant Dis. 73:581-584.

Rupe, J. C., Robbins, R. T., and Gbur, E. E., Jr. 1997. Effect of crop rotation on soil population densities of Fusarium solani and Heterodera glycines and on the development of sudden death syndrome of soybean. Crop Prot. 16: 575-580.

Rupe, J. C., Sabbe, W. E., Robbins, R. T., and Gbur, E. E. 1993. Soil and plant factors associated with sudden death syndrome of soybean. J. Prod. Agric. 6: 218-221.

Scherm, H., and Yang, X. 1996. Development of sudden death syndrome of soybean in relation to soil temperature and soil water matric potential. Phytopathology 86:642-649.

Sjarpe, D., Kandel, Y. R., Chilvers, M., Giesler, L., Malvick, D., McCarville, M., Tenuta, A., Wise, K., and Mueller, D. Multi-location evaluation of fluopyram seed treatment and cultivar on root infection by Fusarium virguliforme, foliar symptom development, and yield of soybean. Can. J. Plant Pathol. In press. doi:10.1080/07060661.2019.1666166

Stephens, P. A., Nickell, C. D., Moots, C. K., and Lim, S. M. 1993. Relationship between field and greenhouse reactions of soybean to Fusarium solani. Plant Dis. 77:163-166.

Tan, R., Collins, P. J., Wang, J., Wen, Z., Boyse, J. F., Laurenz, R. G., Gu, C., Jacobs, J. L., Song, Q., Chilvers, M. I., and Wang, D. 2019. Different loci associated with root and foliar resistance to sudden death syndrome (Fusarium virguliforme) in soybean. Theor. Appl. Genet. 132:501-513.

Van Houwelingen, H. C., Zwinderman, K. H., and Stijnen, T. 1993. A bivariate approach to meta-analysis. Stat. Med. 12:2273-2284.

Vosberg, S. K., Marburger, D. A., Smith, D. L., and Conley, S. P. 2017. Planting date and fluopyram seed treatment effect on soybean sudden death syndrome and seed yield. Agron. J. 109:2570-2578.

Wang, J., Jacobs, J. L., Roth, M. G., and Chilvers, M. I. 2019. Temporal dynamics of Fusarium virguliforme colonization of soybean roots. Plant Dis. 103:19-27.

Wrather, J., and Koenning, S. 2009. Effects of diseases on soybean yields in the United States 1996 to 2007. Plant Health Prog. 10. 